\title{
Reporting quality evaluation of the stroke clinical practice guidelines: a systematic review
}

Shuya Lu ${ }^{1,2+}$, Xufei Luo ${ }^{1 \dagger}$, Xiaojia $\mathrm{Ni}^{3,4^{*}}$, Haoxuan $\mathrm{Li}^{3}$, Miaomiao Meng ${ }^{3}$, Yefeng Cai ${ }^{3,4}$, Yunlan Liu', Mengjuan Ren ${ }^{1}$, Yanrui Sun ${ }^{5}$ and Yaolong Chen ${ }^{1,6,7,8,9^{*}}$

\begin{abstract}
Objectives: To analyze the effectiveness and quality of stroke clinical practice guidelines (CPGs) published in recent years in order to guide future guideline developers to develop better guidelines.

Participants: No patient involved

Method: PubMed, China Biology Medicine (CBM), Wanfang, CNKI, and CPG-relevant websites were searched from January 2015 to December 2019 by two researchers independently. The RIGHT (Reporting Items for Practice Guidelines in Healthcare) checklist was used to assess the reporting quality in terms of domains and items. Then, a subgroup analysis of the results was performed.
\end{abstract}

Primary and secondary outcome measures: RIGHT checklist reporting rate

Results: A total of 66 CPGs were included. Twice as many CPGs were published internationally as were published in China. More than half were updated. Most CPGs are published in journals, developed by societies or associations, and were evidence-based grading. The average reporting rate for all included CPGs was 47.6\%. Basic information got the highest $(71.7 \% \pm 19.7 \%)$ reporting rate, while review and quality assurance got the lowest $(22.0 \% \pm 24.6 \%)$. Then, a cluster analysis between countries, publishing channels, and institutions was performed. There were no statistically significant differences in the reporting quality on the CPGs between publishing countries (China vs. international), publishing channels (journals vs. websites), and institutions (associations vs. non-associations).

Conclusions: Current stroke CPGs reports are of low quality. We recommend that guideline developers improve the quality of reporting of key information and improve the management of conflicts of interest. We recommend that guideline developers consider the RIGHT checklist as an important tool for guideline development.

Trial registration: https://doi.org/10.17605/OSF.IO/PBWUX.

Keywords: Stroke, Clinical practice guidelines, RIGHT, Report quality

\footnotetext{
*Correspondence: grace1984325@126.com; chenyaolong@vip.163.com

†Shuya Lu and Xufei Luo contributed equally to this work.

${ }^{3}$ Guangdong Provincial Hospital of Chinese Medicine, The Second Clinical

School of Chinese Medicine, Guangzhou 510120, People's Republic of China

'School of Public Health, Lanzhou University, Lanzhou 730000, People's

Republic of China

Full list of author information is available at the end of the article
}

(C) The Author(s). 2021 Open Access This article is licensed under a Creative Commons Attribution 4.0 International License, which permits use, sharing, adaptation, distribution and reproduction in any medium or format, as long as you give appropriate credit to the original author(s) and the source, provide a link to the Creative Commons licence, and indicate if changes were made. The images or other third party material in this article are included in the article's Creative Commons licence, unless indicated otherwise in a credit line to the material. If material is not included in the article's Creative Commons licence and your intended use is not permitted by statutory regulation or exceeds the permitted use, you will need to obtain permission directly from the copyright holder. To view a copy of this licence, visit http://creativecommons.org/licenses/by/4.0/ The Creative Commons Public Domain Dedication waiver (http://creativecommons.org/publicdomain/zero/1.0/) applies to the data made available in this article, unless otherwise stated in a credit line to the data. 


\section{Strengths and limitations of this study Strengths}

Provided a comprehensive systematic review of the reporting quality of stroke CPGs published in journals firstly.

\section{Limitations}

The RIGHT checklist is primarily used for the writing of normative CPGs, which determines the completeness and transparency of reporting in CPGs. It is neither to be used as a measure of quality and internal validity nor as a tool for assessing the quality of reporting in published CPGs.

We searched both the English and Chinese libraries, so that the Chinese guidelines are more complete and account for a higher percentage of the total.

\section{Background}

Stroke, including ischemic and hemorrhagic stroke, is a common and serious global health care problem, the second leading cause of death worldwide [1], and one of the leading causes of death and disability in China [2]. In 1978, the World Health Organization (WHO) defined stroke as a clinical syndrome typically characterized by a rapidly developing focal or systemic disturbance of brain function resulting from a sudden rupture or obstruction of a blood vessel in the brain, lasting more than $24 \mathrm{~h}$ or resulting in death [3]. The Global Burden of Disease (GBD) 2016 Stroke Lifetime Risk Collaborators published the results of the global lifetime risk of stroke in The New England Journal of Medicine, we found China had the highest estimated risk (39.3\%; 95\% uncertainty interval, 37.5 to 41.1 ) among 195 countries and states [4], with more than two million new cases per year according to the China Socio-Demographic Index (SDI) as measured in an article from The Lancet $[5,6]$. Moreover, the cost of treating stroke places a heavy mental and economic burden on countries and families $[7,8]$, which is expected to increase further due to an aging population; persistent risk factors, such as high blood pressure; and poor management. Greater than half of China's population lives in rural areas where the overall incidence of stroke is higher (298 per 100,000 person-years) compared with urban areas (204 per 100,000 personyears) [9]. A study published in The Lancet shows that stroke prevalence in rural China increased sharply between 2003 and 2013 [5]. High-quality guidelines can better guide clinical practice. And, standardizing the reporting format of guidelines can facilitate readers' understanding of guidelines and promote the promotion of guidelines, which are necessary qualities of high-quality guidelines. However, primary medical institutions lack clinical practice guidelines (CPGs) to provide scientific and effective services to stroke patients. Therefore, there is an urgent need to standardize the reporting quality of CPGs for stroke.

With the rapid development of the field of stroke medicine and methodology, the institutions that develop guidelines also paid more attention to stroke. In the past 5 years, many CPGs on stroke have been published in China and internationally. The reporting quality of CPGs greatly affects the reliability of the recommendations of the report and determines the length and breadth of the promotion and dissemination of the guideline, so the reporting quality of the guidelines cannot be ignored. However, relevant research worldwide on the reporting standards and quality evaluation of stroke CPGs is lacking. RIGHT (Reporting Items for Practice Guidelines in Healthcare) checklist is the global reporting standard applicable to guide health policies and systems, public health, and clinical medicine [10]. We intended to use the RIGHT standard to evaluate the reporting quality of stroke CPGs in China and abroad in the past 5 years to provide references for improving the quality and reporting standards formulated by the guidelines.

\section{Method \\ Search strategy}

Two researchers searched the following databases independently: PubMed, CBM, Wanfang, China National Knowledge Infrastructure (CNKI), and guideline-related websites, including the National Institute for Health and Care Excellence (NICE), Guidelines International Network (GIN), Scottish Intercollegiate Guidelines Network (SIGN) (http://www.sign.ac.uk), United States Preventive Service Task Force (USPSTF) (https://www. uspreventiveservicestaskforce.org/uspstf/), Canadian Task Force in Preventive Health Care (CTFPHC) (https://canadiantaskforce.ca/), and WHO (http://www. who.int/publications/guidelines/en/). The language restrictions were Chinese or English, and the retrieval time was from January 2015 to December 2019. Before publication, we searched Google Scholar and the official websites of stroke-related journals or organizations to obtain supplemental references, including the WSO (https:// www.world-stroke.org/), Stroke Foundation (https:// strokefoundation.org.au/), Canadian Stroke Best Practices (https://www.strokebestpractices.ca/), and HSF Canadian Partnership for Stroke Recovery (http://www. canadianstroke.ca/). Additional stroke CPGs that were not included were reviewed until December 2019. A search strategy used the keywords "cerebrovascular"," "stroke," "brain"," "guideline"," "guidance," and "guide." We contacted the official or corresponding author by email to obtain the full text of CPGs that were not available. 


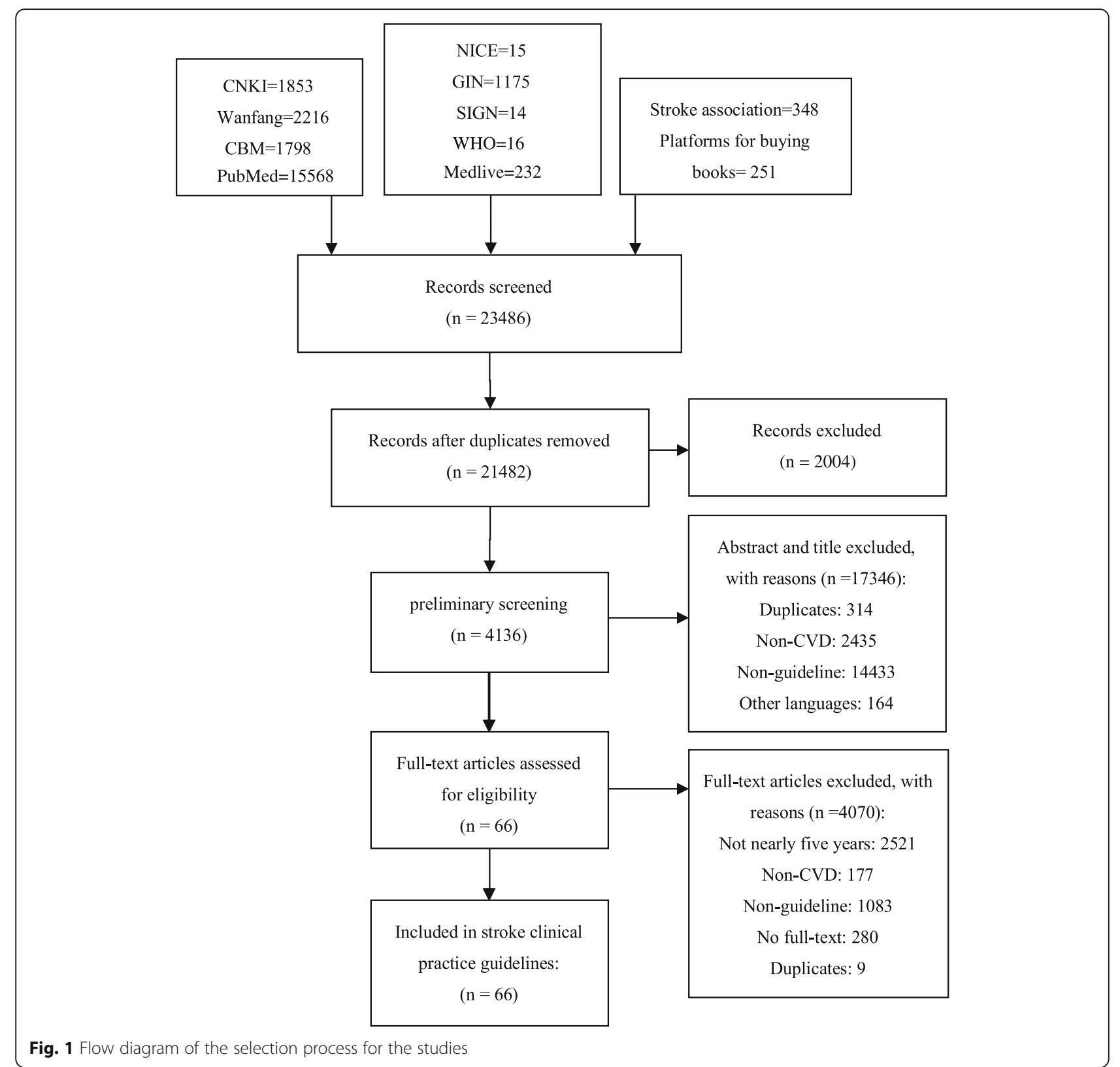

\section{Inclusion and exclusion criteria}

\section{Inclusion criteria}

(1) Related to the theme of stroke; (2) published as a guideline; (3) published in English or Chinese; (4) published in a journal or website.

\section{Exclusion criteria}

(1) Translation, excerpt, and interpretation of guideline;

(2) full text of the guideline is not available; (3) old version of the guideline; (4) bibliographic guideline and guideline proposal; (5) guidelines that are not related to stroke or only contain some stroke content.

\section{RIGHT statement}

The RIGHT checklist is an international standard for guiding the writing and reporting of CPGs for makers of clinical, public health, and other health care fields. RIGHT assists journal editors and peer reviewers in reviewing the CPGs as well as researchers in evaluating and researching them. In contrast to the AGREE checklist, which is dedicated to evaluating the methodological quality of the guideline, the RIGHT checklist is used to assess the reporting quality of the guideline. Therefore, we refer to the quality of the CPGs in the study as the quality of reporting, not the overall quality of the CPGs or methodological quality. In January 2017, the full text 


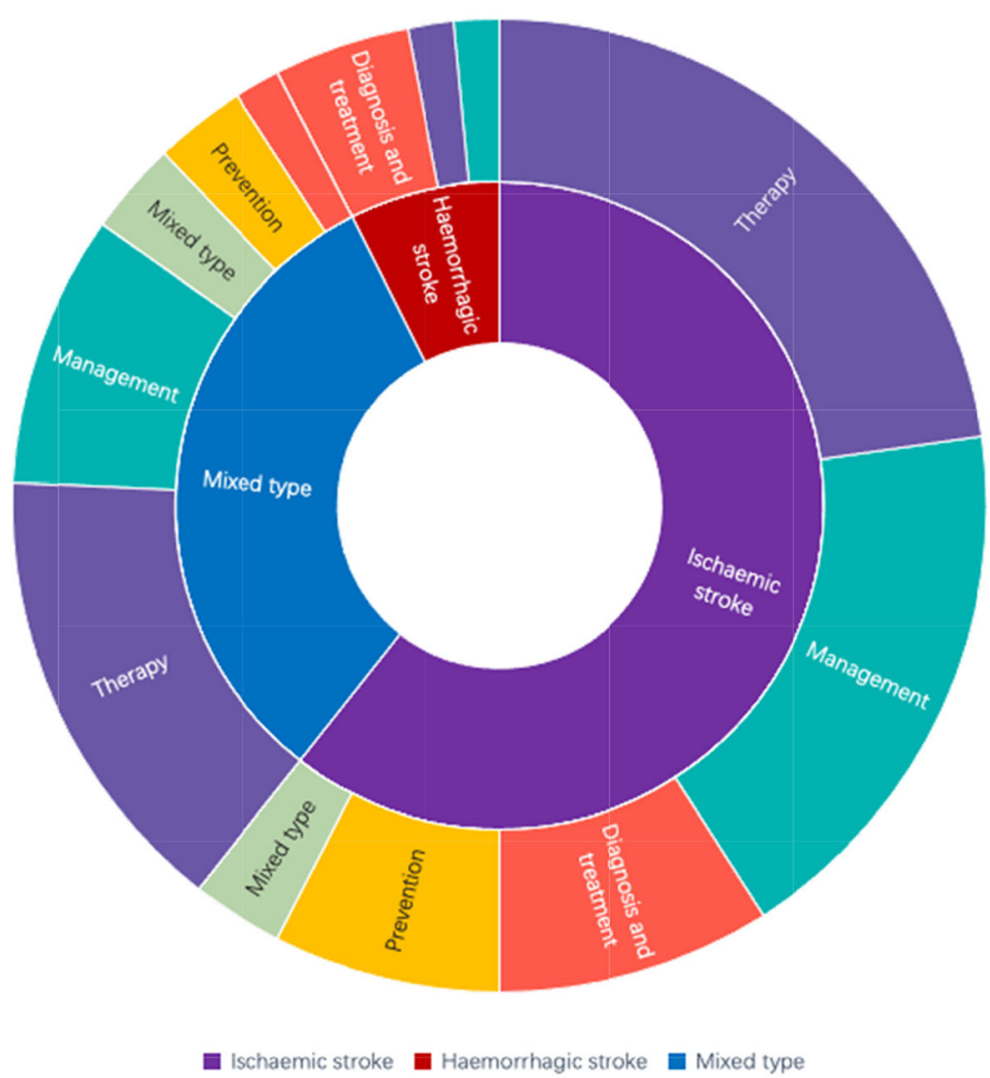

Fig. 2 Types of stroke and areas of concern in stroke CPGs

of the RIGHT statement was published in the Annals of Internal Medicine and includes 22 items: Basic information (items 1-4), background (items 5-9), evidence (items 10-12), recommendations (items 13-15), review and quality assurance (items 16-17), funding and declaration and management of interests (items 18-19), and other information (items 20-22).

\section{Literature screening}

Six researchers were divided into three groups to extract data separately, and the groups were combined and agreed upon after back-to-back extraction, and negotiated with a third party in case of disagreement. The author explained the screening rules to the researcher before screening the literature, excluded literature that was published too early, read the title and abstract, excluded irrelevant literature, and reserved and included the literature. Furthermore, researchers read the full text of the literature that could be accurately judged. If the eligibility of the article was still not determined, it was submitted to the author and subjected unified processing to determine whether it should be included.

\section{Data extraction and reporting quality assessment}

Before data extraction and formal evaluation, 6 researchers (Shuya Lu, Xufei Luo, Mengjuan Ren, Yunlan Liu, Yanrui Sun, and Ting Zhang) were systematically trained on the RIGHT checklist, and two rounds of pretests were completed to ensure that the researchers' understanding of each item was consistent. The data extraction table was designed based on the RIGHT checklist. The six fellows were divided into three groups of two each. Every two researchers independently extracted and cross-checked the information of the included CPGs and negotiated with the third party to solve the differences. The extracted data mainly include the following:

(1) The general characteristics of the guideline include title, publication year, country, organization, and whether referred to AGREE and RIGHT checklist.

(2) Each item of the reporting content of the guideline was evaluated as reported," "partial reported," "unreported," and "not applicable." We evaluated the reporting quality of the included CPGs based on 7 domains and 35 items according to the RIGHT checklist. "Reported": relevant information is fully presented; 
"Unreported": applicable to situations where there is no complete lack of relevant information; "Partially reported": only part of the content is presented; "Not applicable": the guideline does not meet the evaluation requirements of an item and cannot be evaluated as "Reported," "Partially reported," or "Unreported."

\section{Statistical analysis}

We used the Microsoft Excel 2016 software and R studio to summarize the reporting rates and percentages of the RIGHT items and domains for the guideline and presented the results graphically. Then, the relevant basic information (source of CPGs, year of publication, whether the CPGs were developed by associations/societies) was analyzed by meta-analysis based on subgroups, and statistical data were processed by the RStudio software. We followed the PRISMA checklist for reporting results [11]. For information that could not be quantified, we performed a narrative analysis.

\section{Patient and public involvement}

No patient involved.

\section{Results}

According to the pre-developed retrieval strategy, a total of 23,486 related literature was obtained, and 66 studies related to stroke were obtained by searching the Chinese and English databases. The literature screening process and results are shown in Fig. 1.

\section{Basic characteristics of the included CPGs}

The types of stroke and the distribution of areas of interest in the stroke CPGs are shown in Fig. 2. According to the classification of problems concerned with stroke, we divided the CPGs into five categories with maximum numbers focusing on therapy (39.4\%) and management (28.8\%) and least on prevention (10.6\%). Most of them were ischemic stroke CPGs (60.6\%). The basic features of the included CPGs are shown in Table 1. During the past 5 years, China published approximately half as many CPGs (33.3\%) as those published abroad (66.7\%). Other countries and regions that have published stroke CPGs include the USA (19.7\%), Canada (15.2\%), Europe (10.6\%), Australia (6.1\%), Korea (6.1\%), the UK (4.6\%), Brazil (1.5\%), Japan (1.5\%), and India (1.5\%). Most CPGs were published in 2019, whereas the least were published in 2017 and 2018. Only 15 (22.7\%) CPGs were published on the website of the association or society. In terms of developed institutions, most CPGs were produced by various societies or associations (92.4\%). According to the type of version, the number of original CPGs (43.9\%) was approximately equal to updated CPGs (56.1\%). A considerable number of CPGs (83.3\%) had an evidence-based rating.
Table 1 Characteristics of the CPGs included $(n=66)$ [12-77]

\begin{tabular}{|c|c|c|}
\hline Categories & Number & $\%$ \\
\hline \multicolumn{3}{|l|}{ Country } \\
\hline China & 22 & $33.3 \%$ \\
\hline International & 44 & $66.7 \%$ \\
\hline \multicolumn{3}{|l|}{ Publication year } \\
\hline 2015 & 14 & $21.2 \%$ \\
\hline 2016 & 14 & $21.2 \%$ \\
\hline 2017 & 10 & $15.2 \%$ \\
\hline 2018 & 10 & $15.2 \%$ \\
\hline 2019 & 18 & $27.3 \%$ \\
\hline \multicolumn{3}{|l|}{ Publication } \\
\hline Journal & 51 & $77.3 \%$ \\
\hline Website & 15 & $22.7 \%$ \\
\hline \multicolumn{3}{|l|}{ Organization } \\
\hline Societies/associations & 61 & $92.4 \%$ \\
\hline Non-societies/associations & 5 & $7.6 \%$ \\
\hline \multicolumn{3}{|l|}{ Type of version } \\
\hline Original & 29 & $43.9 \%$ \\
\hline Updated & 37 & $56.1 \%$ \\
\hline \multicolumn{3}{|l|}{ Evidence-based grading } \\
\hline Yes & 55 & $83.3 \%$ \\
\hline No & 11 & $16.7 \%$ \\
\hline
\end{tabular}

\section{Quality of reporting}

Only 3 (4.6\%) CPGs stated that they followed the guideline development tool, and all 3 followed the AGREE checklist. The 66 stroke CPGs were evaluated by 22 items in the RIGHT checklist with an average reporting rate of $47.6 \%$. The reporting quality of each domain and each item are shown in Figs. 3 and 4 and Table 2.

Regarding the quality of reporting, the highest and lowest reporting rates were domain 1 (basic information, 71.6\%) and domain 5 (review and quality assurance, $21.8 \%$ ), respectively (Fig. 3). In addition, it is important to note that the overall quality of the report is affected by the fact that some of the items are not applicable in domains 3, 4, and 6 (Fig. 4).

In 7 domains of the RIGHT checklist, the largest difference in reporting rates between Chinese and International CPGs for stroke was $30.7 \%$ in domain 6 (funding, declaration, and management of interest) followed by domain 5 (difference of $22.7 \%$ ) and domain 3 (difference of 19.6\%). The smallest differences between Chinese and international CPGs were found in domain 1 (difference of $6.1 \%$ ) and domain 2 (difference of 3.2\%) with a higher reporting rate for Chinese than international CPGs in domain 1 (Fig. 5).

Of all the CPGs, 12 (18.2\%) scored greater than 60\%, and 8 (12.1\%) scored less than $30 \%$. Regarding each item, 


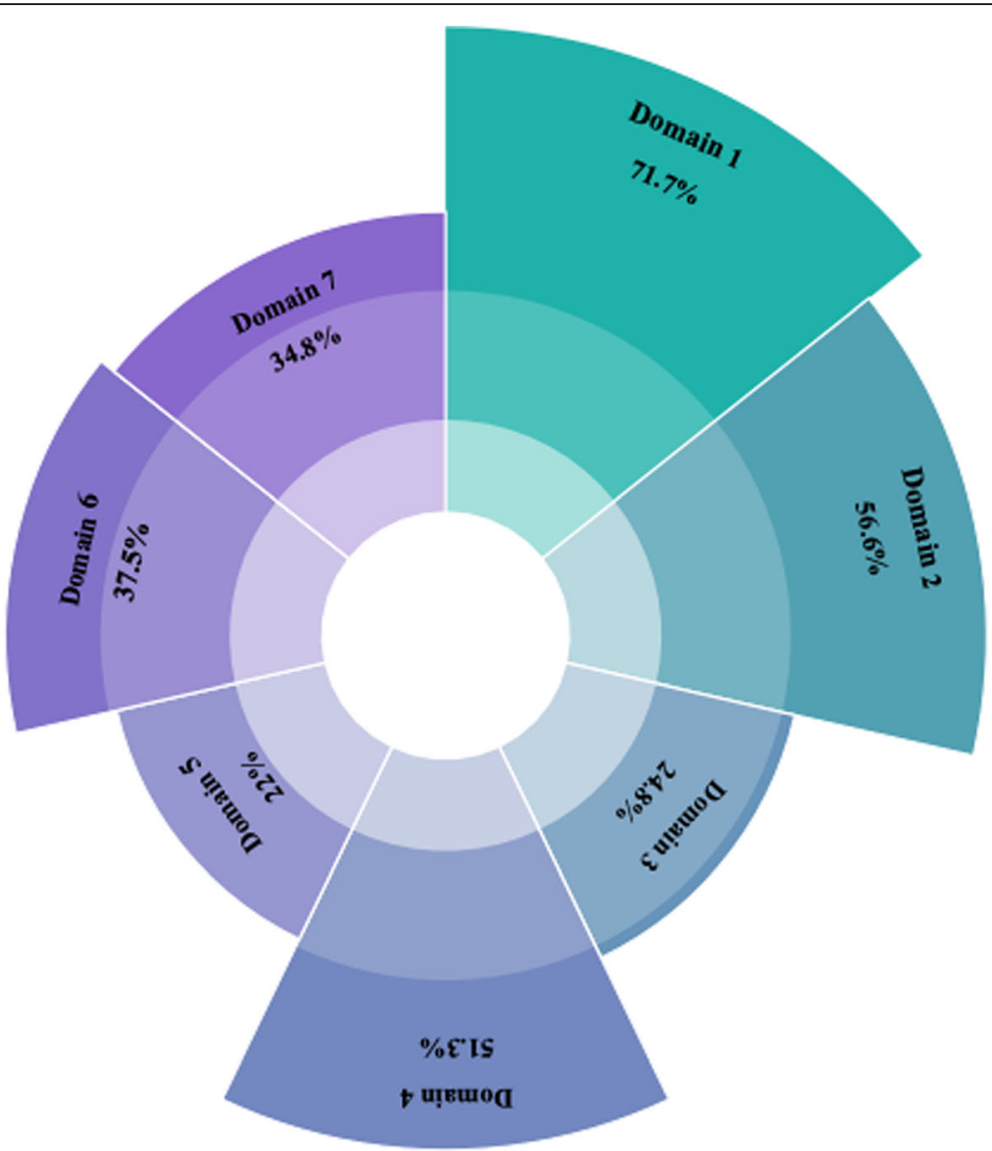

Fig. 3 Distribution of reporting rates by domain in the Clinical Guidelines RIGHT checklist. Domain 1: basic information; domain 2: background; domain 3: evidence; domain 4: recommendations; domain 5: review and quality assurance; domain 6: funding, declaration, and management of interest; domain 7: other information

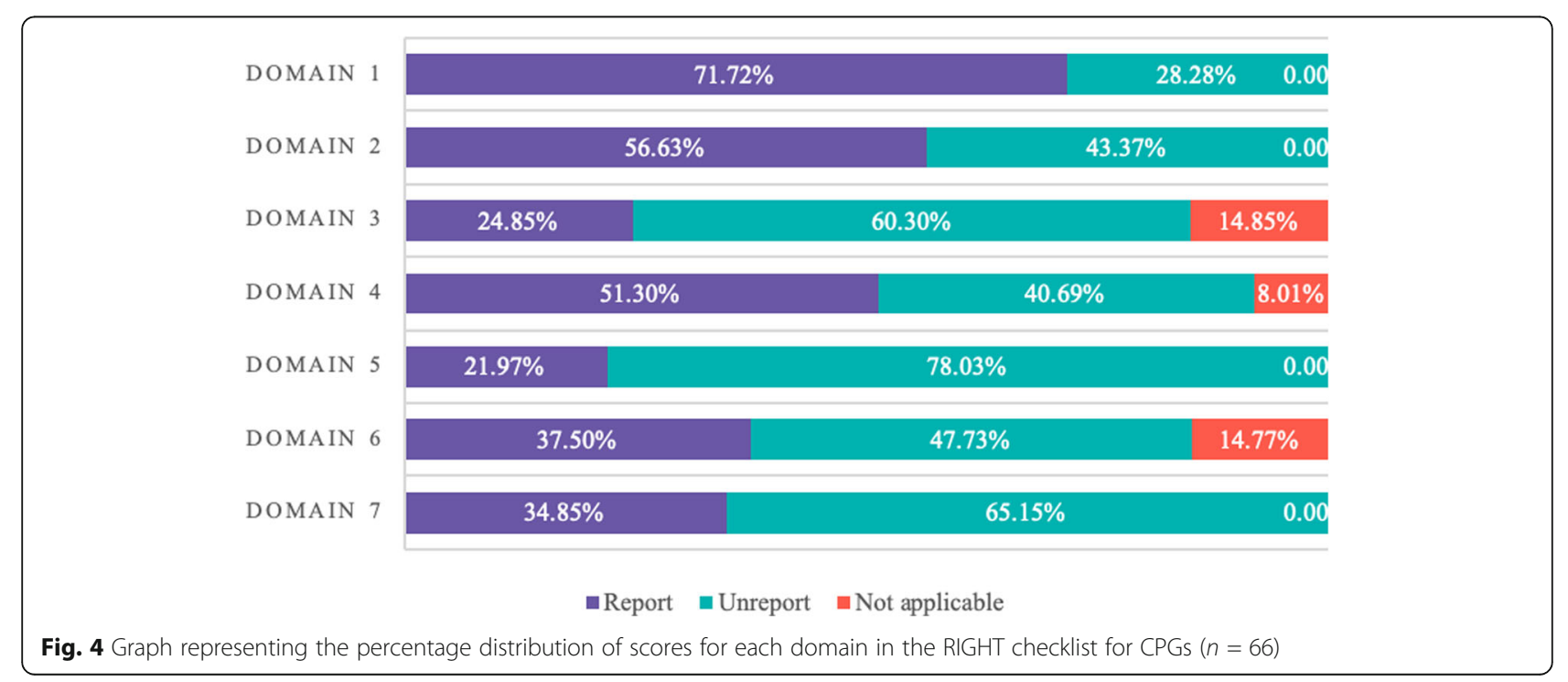


Table 2 Distribution of scores and percentages for each item in the RIGHT checklist for the included CPGs ( $n=66)$

\section{RIGHT checklist}

\begin{tabular}{|c|c|c|}
\hline Reported & $\begin{array}{l}\text { Not } \\
\text { reported }\end{array}$ & $\begin{array}{l}\text { Not } \\
\text { applicable }\end{array}$ \\
\hline$N \quad(0$ & $N \quad(\%)$ & (\%) \\
\hline
\end{tabular}

\section{Basic information}

1 a Identify the report as a guideline, that is, with "guideline(s)" or "recommendation(s)" in the title.

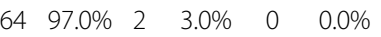

$1 \mathrm{~b}$ Describe the year of publication of the guideline.

1c Describe the focus of the guideline, such as screening, diagnosis, treatment, management, prevention or others.

2 Provide a summary of the recommendations contained in the guideline.

3 Define new or key terms, and provide a list of abbreviations and acronyms if applicable.

4 Identify at least one corresponding developer or author who can be contacted about the guideline.

Background

5 Describe the basic epidemiology of the problem, such as the prevalence/incidence, morbidity, mortality, and burden (including financial) resulting from the problem.

6 Describe the aim(s) of the guideline and specific objectives, such as improvements in health indicators (e.g., mortality and disease prevalence), quality of life, or cost savings.

$7 a$ Describe the primary population(s) that is addressed by the recommendation(s) in the guideline.

$7 b$ Describe any subgroups that are given special consideration in the guideline.

8a Describe the intended primary users of the guideline (such as primary care providers, clinical specialists, public health practitioners, program managers, and policy-makers) and other potential users of the guideline.

8b Describe the setting(s) for which the guideline is intended, such as primary care, low- and middle-income countries, or in-patient facilities.

9a Describe how all contributors to the guideline development were selected and their roles and responsibilities (e.g., steering group, guideline panel, external reviewer, systematic review team, and methodologists).

9b List all individuals involved in developing the guideline, including their title, role(s) and institutional affiliation(s).

$\begin{array}{llllll}45 & 68.2 \% & 21 & 31.8 \% & 0 & 0.0 \%\end{array}$

$54 \quad 81.8 \% \quad 12 \quad 18.2 \% \quad 0 \quad 0.0 \%$

$26 \quad 39.4 \% \quad 40 \quad 60.6 \% \quad 0 \quad 0.0 \%$

$\begin{array}{llllll}42 & 63.6 \% & 24 & 36.4 \% & 0 & 0.0 \%\end{array}$

$\begin{array}{llllll}53 & 80.3 \% & 13 & 19.7 \% & 0 & 0.0 \%\end{array}$

$\begin{array}{llllll}40 & 60.6 \% & 26 & 39.4 \% & 0 & 0.0 \%\end{array}$

$53 \quad 80.3 \% \quad 13 \quad 19.7 \% \quad 0 \quad 0.0 \%$

$\begin{array}{lllllll}32 & 48.5 \% & 34 & 51.5 \% & 0 & 0.0 \%\end{array}$

$\begin{array}{llllll}10 & 15.2 \% & 56 & 84.8 \% & 0 & 0.0 \%\end{array}$

$\begin{array}{llllll}42 & 63.6 \% & 24 & 36.4 \% & 0 & 0.0 \%\end{array}$

$23 \quad 34.8 \% \quad 43 \quad 65.2 \% \quad 0 \quad 0.0 \%$

$\begin{array}{lllllll}48 & 72.7 \% & 18 & 27.3 \% & 0 & 0.0 \%\end{array}$

$51 \quad 77.3 \% \quad 15 \quad 22.7 \% \quad 0 \quad 0.0 \%$

Evidence

10a State the key questions that were the basis for the recommendations in PICO (population, intervention, comparator, and outcome) or other format as appropriate.

$10 \mathrm{~b}$ Indicate how the outcomes were selected and sorted.

11a Indicate whether the guideline is based on new systematic reviews done specifically for this guideline or whether existing systematic reviews were used.

$11 \mathrm{~b}$ If the guideline developers used existing systematic reviews, reference these and describe how those reviews were identified and assessed (provide the search strategies and the selection criteria, and describe how the risk of bias was evaluated) and whether they were updated.

12 Describe the approach used to assess the certainty of the body of evidence.

$11 \quad 16.7 \% \quad 55 \quad 83.3 \% \quad 0$

$0.0 \%$

$5 \quad 7.6 \% \quad 61 \quad 92.4 \% \quad 0 \quad 0.0 \%$

$22 \quad 33.3 \% \quad 44 \quad 66.7 \% \quad 0 \quad 0.0 \%$

$12 \quad 18.2 \% \quad 5 \quad 7.6 \% \quad 49 \quad 74.2 \%$

$32 \quad 48.5 \% \quad 34 \quad 51.5 \% \quad 0 \quad 0.0 \%$

Recommendations

13a Provide clear, precise, and actionable recommendations.

13b Present separate recommendations for important subgroups if the evidence suggests that there are important differences in factors influencing recommendations, particularly the balance of benefits and harms across subgroups.

13c Indicate the strength of recommendations and the certainty of the supporting evidence.

$55 \quad 83.3 \% \quad 5 \quad 7.6 \% \quad 6 \quad 9.1 \%$

14a Describe whether values and preferences of the target population(s) were considered in the formulation of $\quad 32 \quad \begin{array}{lllll}48.5 \% & 34 & 51.5 \% & 0 & 0.0 \%\end{array}$ each recommendation. If yes, describe the approaches and methods used to elicit or identify these values and preferences. If values and preferences were not considered, provide an explanation.

14b Describe whether cost and resource implications were considered in the formulation of recommendations. If yes, describe the specific approaches and methods used (such as cost-effectiveness analysis) and summarize the results. If resource issues were not considered, provide an explanation.

14c Describe other factors taken into consideration when formulating the recommendations, such as equity, feasibility and acceptability.

$38 \quad 57.6 \% \quad 28 \quad 42.4 \% \quad 0 \quad 0.0 \%$

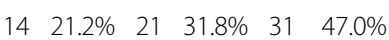

$27 \quad 40.9 \% \quad 39 \quad 59.1 \% \quad 0 \quad 0.0 \%$

$34 \quad 51.5 \% \quad 32 \quad 48.5 \% \quad 0 \quad 0.0 \%$

15 Describe the processes and approaches used by the guideline development group to make decisions,

$37 \quad 56.1 \% \quad 29 \quad 43.9 \% \quad 0 \quad 0.0 \%$ 
Table 2 Distribution of scores and percentages for each item in the RIGHT checklist for the included CPGs ( $n=66)$ (Continued)

\begin{tabular}{|c|c|c|c|c|c|c|c|}
\hline \multicolumn{2}{|c|}{ RIGHT checklist } & \multicolumn{2}{|c|}{ Reported } & \multicolumn{2}{|c|}{$\begin{array}{l}\text { Not } \\
\text { reported }\end{array}$} & \multicolumn{2}{|c|}{$\begin{array}{l}\text { Not } \\
\text { applicable }\end{array}$} \\
\hline & & $N$ & (\%) & $N$ & (\%) & $N$ & $(\%)$ \\
\hline & $\begin{array}{l}\text { particularly the formulation of recommendations (such as how consensus was defined and achieved and } \\
\text { whether voting was used). }\end{array}$ & & & & & & \\
\hline \multicolumn{8}{|c|}{ Review and quality assurance } \\
\hline 16 & $\begin{array}{l}\text { Indicate whether the draft guideline underwent independent review and, if so, how this was executed and } \\
\text { the comments considered and addressed. }\end{array}$ & 26 & $39.4 \%$ & 40 & $60.6 \%$ & 0 & $0.0 \%$ \\
\hline 17 & Indicate whether the guideline was subjected to a quality assurance process. If yes, describe the process. & 3 & $4.5 \%$ & 63 & $95.5 \%$ & 0 & $0.0 \%$ \\
\hline \multicolumn{8}{|c|}{ Funding, declaration and management of interest } \\
\hline $18 a$ & Describe the specific sources of funding for all stages of guideline development. & 27 & $40.9 \%$ & 39 & $59.1 \%$ & 0 & $0.0 \%$ \\
\hline $18 \mathrm{~b}$ & $\begin{array}{l}\text { Describe the role of the funder(s) in the different stages of guideline development and in the } \\
\text { dissemination and implementation of the recommendations. }\end{array}$ & 1 & $1.5 \%$ & 26 & $39.4 \%$ & 39 & $59.1 \%$ \\
\hline $19 a$ & Describe what types of conflicts (financial and non-financial) were relevant to guideline development. & 49 & $74.2 \%$ & 17 & $25.8 \%$ & 0 & $0.0 \%$ \\
\hline $19 \mathrm{~b}$ & $\begin{array}{l}\text { Describe how conflicts of interest were evaluated and managed and how users of the guideline can access } \\
\text { the declarations. }\end{array}$ & 22 & $33.3 \%$ & 44 & $66.7 \%$ & 0 & $0.0 \%$ \\
\hline \multicolumn{8}{|c|}{ Other information } \\
\hline 20 & Describe where the guideline, its appendices, and other related documents can be accessed. & 27 & $40.9 \%$ & 39 & $59.1 \%$ & 0 & $0.0 \%$ \\
\hline 21 & Describe the gaps in the evidence and/or provide suggestions for future research. & 27 & $40.9 \%$ & 39 & $59.1 \%$ & 0 & $0.0 \%$ \\
\hline 22 & $\begin{array}{l}\text { Describe any limitations in the guideline development process (such as the development groups were not } \\
\text { multidisciplinary or patients' values and preferences were not sought), and indicate how these limitations } \\
\text { might have affected the validity of the recommendations. }\end{array}$ & 15 & $22.7 \%$ & 51 & $77.3 \%$ & 0 & $0.0 \%$ \\
\hline
\end{tabular}

the results showed that items 1a (97.0\%), 13c (83.3\%), and 1c $(81.8 \%)$ scored higher than the other items, whereas items $10 \mathrm{~b}(7.6 \%), 17(4.5 \%)$, and $18 \mathrm{~b}(1.5 \%)$ were mainly distributed in the very low levels (Table 2).

\section{Subgroup analysis}

By comparing the reports of stroke CPGs under different classification methods, the following information was obtained (Figs. 6, 7, 8, 9):
The reporting quality of 22 CPGs published in China in the RIGHT checklist is lower than that of 44 published abroad, but the difference is not statistically significant. For items with statistically significant differences in reporting rates between China and International CPGs, the International CPGs have a higher reporting quality in items 11a, 15, 16, 18a, 19a, 19b, and 20.

The average reporting quality of the RIGHT checklist was similar in the CPGs published by journals compared

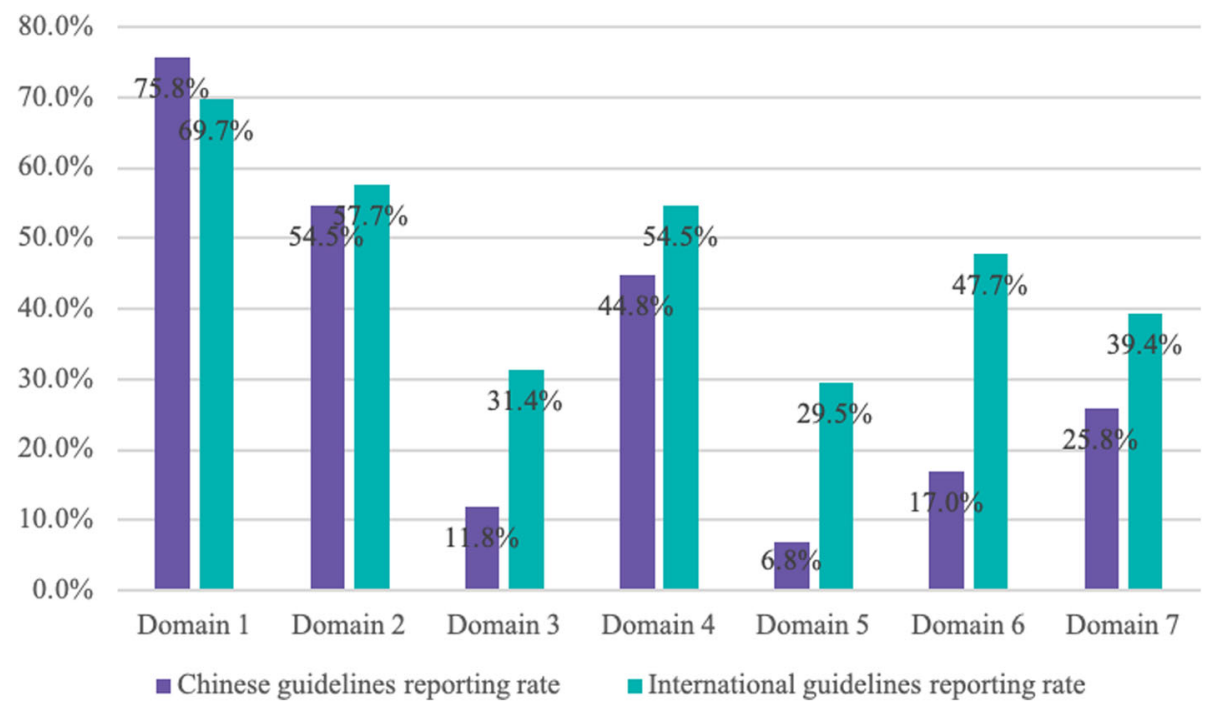

Fig. 5 Comparison of adherence of RIGHT domains of Chinese and international stroke CPGs 


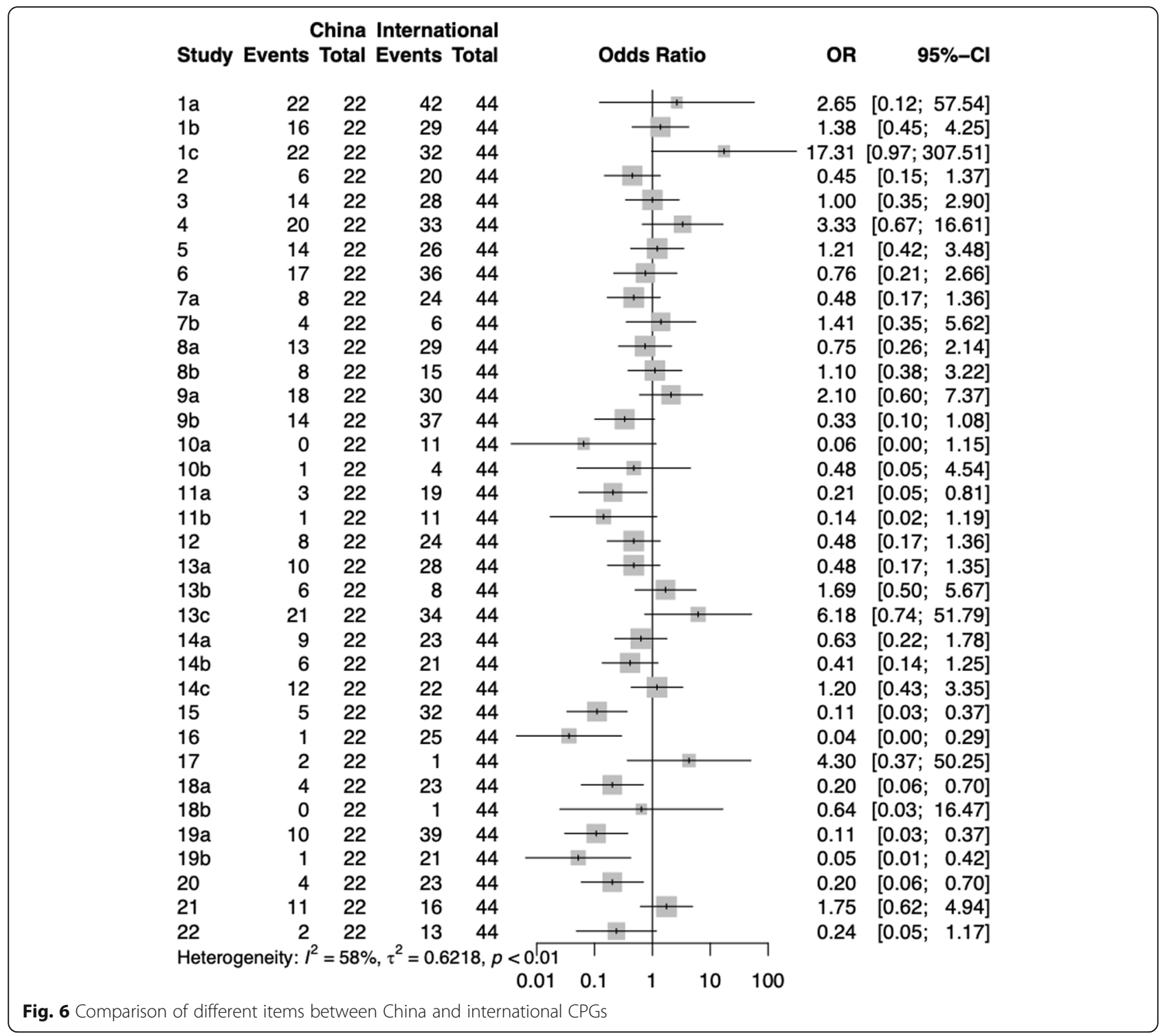

with those published on the websites, and the difference was not statistically significant. In items 3 and 14b, CPGs published by journals were significantly lower than websites; however, in items 4 and 13c, the reporting quality of guideline published in journals was higher.

The average reporting quality of 61 CPGs developed by various societies OR associations was higher than that of 5 CPGs developed by non-societies OR associations without statistically significant differences. For specific items, the institute/association CPGs have a higher reporting quality in items $6,8 \mathrm{a}$, and $9 \mathrm{~b}$, whereas noninstitute/association CPGs have the highest reporting quality in item $18 \mathrm{~b}$.

\section{Discussion}

Our study is the first in the world to use the RIGHT checklist to evaluate the report quality of 66 stroke
CPGs published in Chinese and international journals and networks over the past 5 years. Based on the 37item RIGHT checklist, the average reporting rate of 66 CPGs was $47.6 \%$. Domains 1, 2, and 4 had a higher reporting rates, whereas domains 3,5 , and 7 had the lower reporting rates. The significant preponderance of evidence-based CPGs indicates the overall high quality of stroke CPGs in the methodological field. This finding is consistent with the report quality evaluation results of CPGs for traditional Chinese medicine and CPGs for common public health diseases affecting the health of the Chinese population, such as diabetes [78, 79].

Two-thirds of the CPGs are ischemic stroke, and only a small proportion is specific for hemorrhagic stroke. This discrepancy may be due to the increased incidence and disease burden of ischemic stroke compared with hemorrhagic stroke. According to the 2019 China 


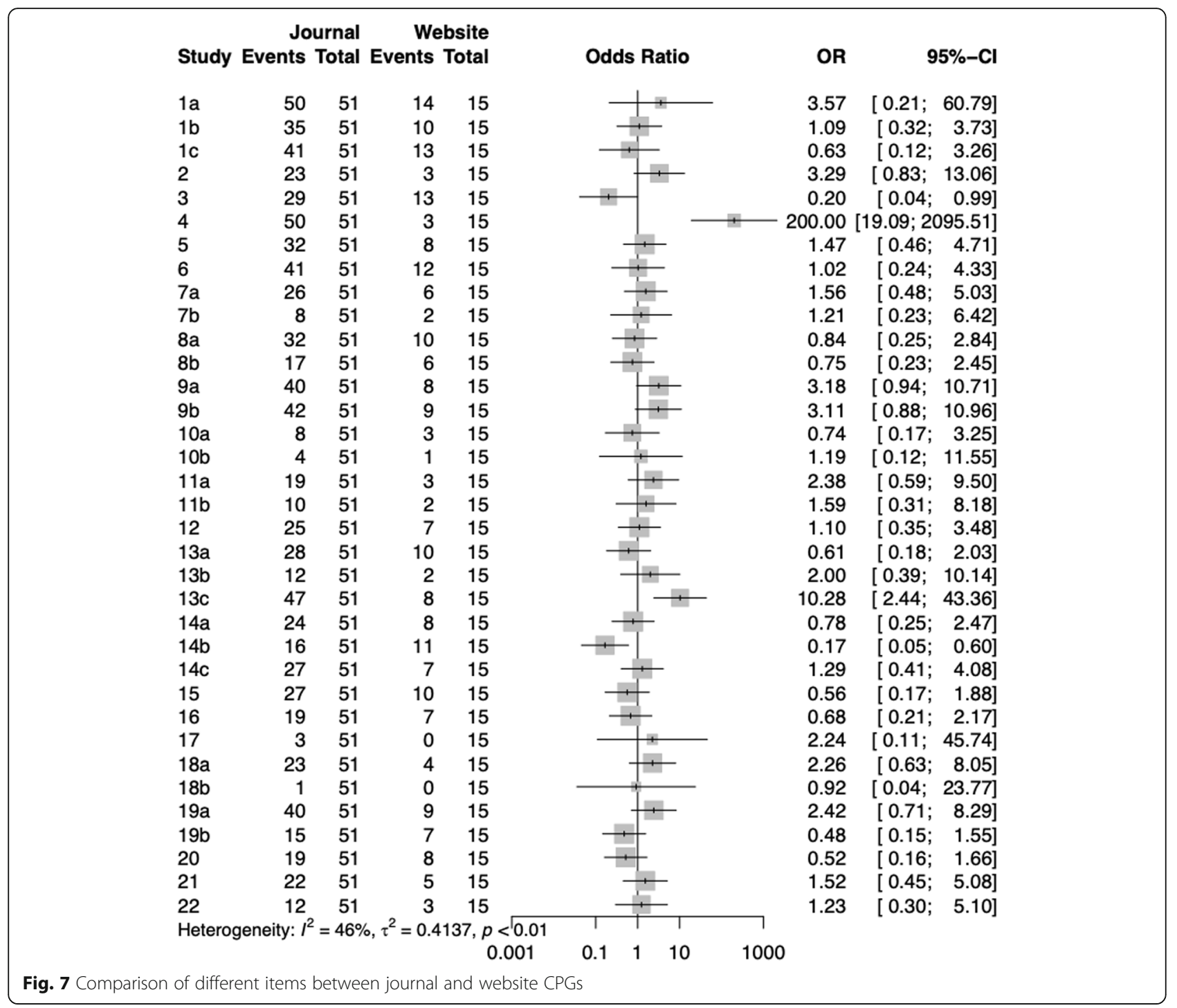

Statistical Yearbook of Health and Family Planning, the incidence of ischemic stroke and disability-adjusted life expectancy increased yearly between 2005 and 2017, whereas the incidence of hemorrhagic stroke decreased yearly. In addition, the recurrence rate of ischemic stroke is higher, and the number of hospital discharges and per capita medical costs have dramatically increased.

We found here are much more Stroke CPGs in China compared to the rest of the world. This may be related to the aging of the Chinese population and the dramatic increase in stroke prevalence in rural China between 2003 and 2013. In conclusion, Chinese society is generally concerned about stroke.

Among stroke topics, treatment and management of CPGs are more common than prevention CPGs, which may be related to the emphasis on treatment over prevention in clinical practice. The INTERSTROKE study from 32 countries around the world showed that $90.7 \%$ of strokes worldwide were associated with 10 interventional risk factors [80]. For the Chinese population, these 10 risk factors were associated with $94.3 \%$ of strokes. This finding suggests that stroke is preventable and that primary prevention is a fundamental measure to reduce the incidence of stroke. However, current prevention guidelines of stroke focus more on secondary prevention. Stroke guidelines should pay more attention to prevention and management. In particular, there is a need to make efforts in the guidelines for the primary prevention of stroke.

Among the specific items, the reporting rates of $10 \mathrm{~b}$, 17 , and $18 \mathrm{~b}$ were very low, and only one guideline reported item 18b. Regarding item 18b, we found that the low reporting rate was not equal to low quality given the high rate of not applicable guidelines (54.9\%). Taking the above into account, we decided to use the non- 


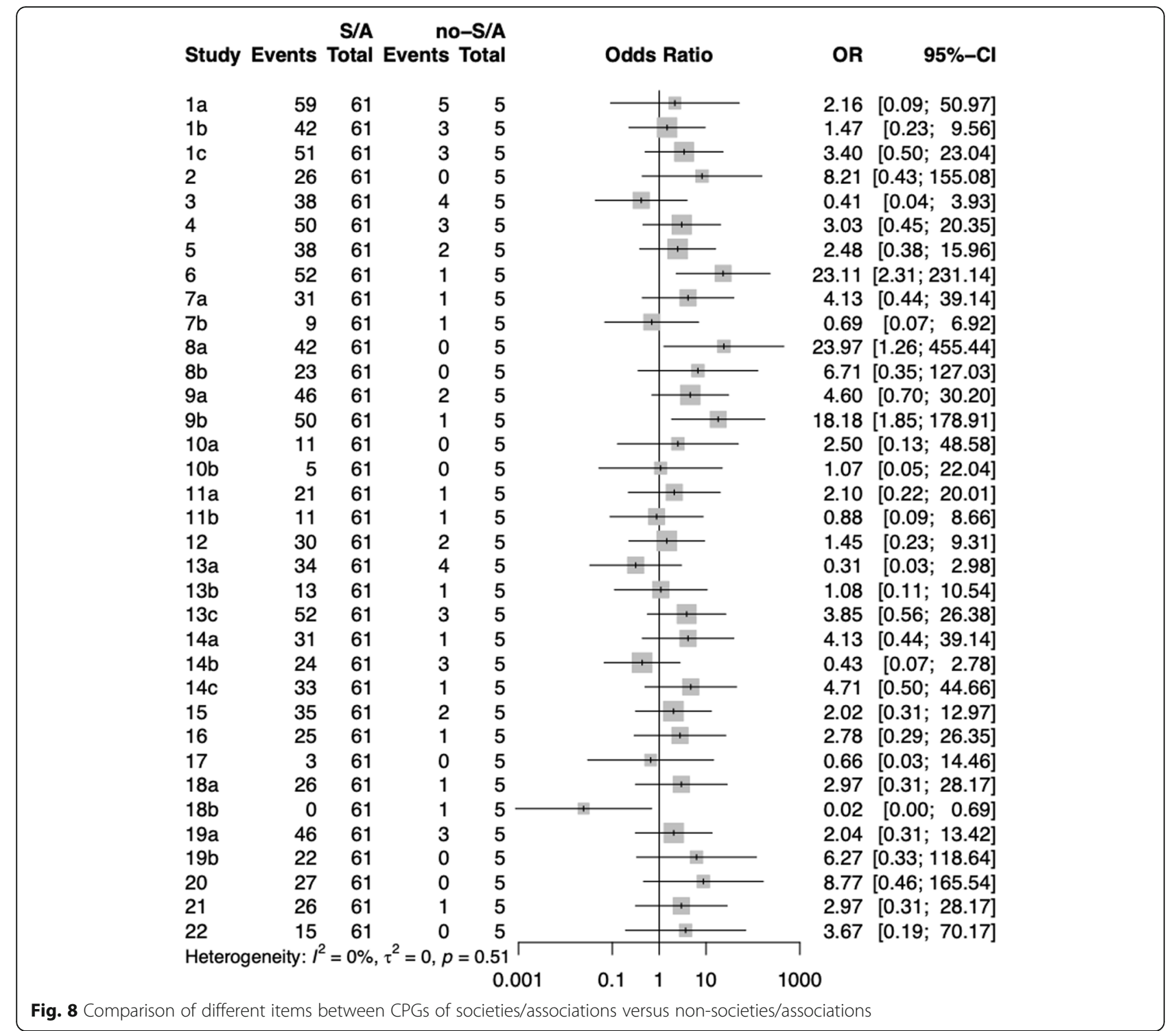

reporting rate as a proxy for the quality of the guideline. The unreported rates of $7 \mathrm{~b}, 10 \mathrm{a}, 10 \mathrm{~b}$, and 17 items were all greater than $80 \%$, reflecting the numerous shortcomings in the development of stroke CPGs in terms of consideration of subgroups, the key question statement in recommendations, selection of outcome indicators, and the assurance process of quality.

In item $7 \mathrm{~b}$, the CPGs were underreported at the subgroup level. However, the treatment and management were different in younger patients compared with older

\begin{tabular}{|c|c|c|c|c|c|c|c|c|c|c|c|}
\hline \multirow[b]{2}{*}{ Study } & \multicolumn{2}{|r|}{ Experimental } & \multicolumn{3}{|r|}{ Control } & \multirow{2}{*}{\multicolumn{3}{|c|}{ Mean Difference }} & \multirow{2}{*}{\multicolumn{2}{|c|}{ MD }} & \multirow[b]{2}{*}{$95 \%-\mathrm{Cl}$} \\
\hline & Total & Mean & Total & Mean & SD & & & & & & \\
\hline China vs. International & 22 & 0.410 .3050 & 44 & 0.51 & 0.2405 & & + & & & -0.10 & {$[-0.25 ; 0.04]$} \\
\hline journal vs. website & 51 & 0.490 .2616 & 15 & 0.44 & 0.2545 & & F & & & 0.04 & {$[-0.10 ; 0.19]$} \\
\hline association vs. non-societies & 61 & 0.490 .2520 & 5 & 0.30 & 0.2678 & & 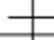 & +1 & & 0.19 & {$[-0.05 ; 0.44]$} \\
\hline \multirow{2}{*}{\multicolumn{3}{|c|}{ Heterogeneity: $I^{2}=58 \%, \tau^{2}=0.0104, p=0.09$}} & & & 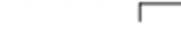 & $T$ & & 1 & $\neg$ & & \\
\hline & & & & & -0.4 & -0.2 & 0 & 0.2 & 0.4 & & \\
\hline
\end{tabular}


patients, and it is necessary to elaborate on age-specific measures by subgroup.

In item 10a, 83.3\% of CPGs did not report key question in recommendations. According to the RIGHT checklist, development, such as PICO (population, intervention, comparator, and outcome), were recommended to state the key question statement in recommendations. The PICO format helps clinical and research professionals find the best available scientific information quickly and accurately when in doubt or question [81].

In item 10b, the outcome indicator is the carrier of evidence classification in the guideline. If the selection method of outcome indicator is not appropriate, it may lead to non-main outcomes, thus reducing the operability of the guideline.

Financial support is essential for the formulation of the CPGs, but it may be related to the conflict of interest in the formulation of the CPGs. The statements of financial support were unclear; guideline developers should document in detail the role of funding in the development, dissemination, and implementation of the CPGs to improve their feasibility and reliability.

According to the study [82], two CPGs published by the American Heart Association and the American Academy of Stroke in 2013 and 2018 involved a total of 34 authors, of whom 12 (35\%) had financial conflicts of interest. Conflicts of interest are inevitable in the formulation of CPGs, so how to manage conflicts of interest is particularly important. The transparency of financial support is an important aspect. Therefore, it is recommended that experts improve the completeness of the reports of each item in the CPGs for stroke to improve the reliability and credibility of the CPGs for stroke clinical practice.

Based on the subgroup analysis of domestic and international CPGs, it cannot be concluded that the Chinese CPGs are significantly different from the international CPGs. Variances may be due to guide-setting practices, author habits, and health service models in China and abroad. In recent years, the development of evidencebased CPGs in China has followed the pace of international countries, and the literature and methodology of CPGs have also matured. However, there is a considerable gap with international guidelines in domain 6 (funding, declaration, and management of interest). Studies have shown that the quality of evidence-based ischemic stroke CPGs in China is greater than that of consensus-based Chinese CPGs and evidence-based and consensus-based Chinese CPGs [83]; China's guideline development agency could enhance China's capacity to provide or coordinate the synthesis of evidence for guideline development and monitor the work of guideline developers. China can use what is known and work with the international community to develop methodologies to address the challenges of evidencebased guidance development [84].

Comparing publication forms, it was found that the reporting quality of CPGs published in journals was similar to that of CPGs published on the website. The reporting rates of items 4 and 13c were much lower than those of the CPGs published in the journal. This finding may be attributed to the fact that the reports published on the website were less standardized and difficult to trace back to the source.

In addition, items $11 \mathrm{~b}, 13 \mathrm{~b}$, and $18 \mathrm{~b}$ in the checklist were excluded from the subgroup analyses due to their high discomfort rates. We do not consider these factors sufficient to affect the quality of our study.

In domain 2 (background), some societies or associations publish CPGs of higher quality than those of nonsocieties or associations. This finding may be due to a combination of more cutting-edge methodology, better staffing, and better institutional processes. The association or society has a better division of the labor system, more experience in developing CPGs, and therefore more strict control over quality. However, regardless of whether the CPGs were issued by an academy or association, the formulation of the CPG working group should be composed of multidisciplinary experts jointly involved in decision-making, in which the CPG methodological experts play a key role [85]. Excellent teamwork ensures the completeness of the report and mass stability.

\section{Conclusion}

In summary, the quality of the existing CPGs for stroke reporting needs to be improved. Guideline developers need to follow relevant guideline reporting and evaluation tools (such as RIGHT), pay attention to the details in the process of guideline reporting and the comprehensiveness of the report, and strengthen the standardization of the guideline to better improve the quality of the guideline such that the guideline improves clinical practice.

\section{Abbreviations}

RIGHT: Reporting Items for Practice Guidelines in Healthcare;

PRISMA: Preferred Reporting Items for Systematic Reviews and MetaAnalyses; CPGs: Clinical Practice Guidelines; CVD: Cerebrovascular Disease;

SDI: Socio-demographic index; GIN: Guidelines International Network; WHO: World Health Organization; NICE: National Institute for Health and Care Excellence; WSO: World Stroke Organization

\section{Acknowledgements \\ Not applicable.}

\section{Authors' contributions}

Chen $\mathrm{Y}$ and $\mathrm{Ni} X$ conceived and designed the manuscript. Lu S and Luo $\mathrm{X}$ analyzed the data and drafted the manuscript. Li H and Meng M participated in literature search. Lu S, Liu Y, Ren M, and Sun Y collected the data. Chen Y, $\mathrm{Ni} X$, and Cai $Y$ interpreted the data. All authors critically reviewed the manuscript and approved the submission. 


\section{Authors' information}

Not applicable.

\section{Funding}

This work was supported by Yefeng Cai with external funding from the Key Disciplinary Research Funding from the Guangzhou University of Chinese Medicine (No. XK2019025), and the National Administration of Traditional Chinese Medicine, China (No. 2019XZZX-NB002), and the Guangzhou University of Chinese Medicine "Double First-class" and high-level university disciplines collaborative innovation team key projects (No. 2021xk26).

\section{Availability of data and materials}

The datasets used and/or analyzed during the current study are available from the corresponding author on reasonable request.

\section{Declarations}

\section{Ethics approval and consent to participate}

This article does not contain any studies with human participants or animals performed by any of the authors.

\section{Consent for publication}

Not applicable.

\section{Competing interests}

All authors have completed the ICMJE uniform disclosure form. The authors declare that they have no competing interests.

\section{Author details}

${ }^{1}$ School of Public Health, Lanzhou University, Lanzhou 730000, People's Republic of China. 'Department of Pediatric, Sichuan Provincial People's Hospital, University of Electronic Science and Technology of China, Chengdu 611731, People's Republic of China. ${ }^{3}$ Guangdong Provincial Hospital of Chinese Medicine, The Second Clinical School of Chinese Medicine Guangzhou 510120, People's Republic of China. ${ }^{4}$ Guangdong Provincial Academy of Chinese Medical Sciences, Guangzhou 510120, People's Republic of China. ${ }^{5}$ The Second Clinical Medical College of Lanzhou University, Lanzhou 730000, People's Republic of China. ${ }^{6}$ Institute of Health Data Science, Lanzhou University, Lanzhou 730000, People's Republic of China. ${ }^{7}$ Evidence-based Medicine Center, School of Basic Medical Sciences, Lanzhou University, Lanzhou 730000, People's Republic of China. ' Lanzhou University, an Affiliate of the Cochrane China Network, Lanzhou 730000, People's Republic of China. ${ }^{9}$ Key Laboratory of Evidence Based Medicine and Knowledge Translation of Gansu Province, Lanzhou University, 730000 Lanzhou, People's Republic of China.

Received: 23 April 2021 Accepted: 2 September 2021

\section{Published online: 30 September 2021}

\section{References}

1. Campbell BCV, De Silva DA, Macleod MR, et al. Ischaemic stroke. Nat Rev Dis Primers. 2019;5(1):70. https://doi.org/10.1038/s41572-019-0118-8.

2. Asakawa T, Zong L, Wang $L$, Xia $Y$, Namba $H$. Unmet challenges for rehabilitation after stroke in China. Lancet. 2017;390(10090):121-2. https:// doi.org/10.1016/S0140-6736(17)31584-2.

3. World Health Organization. Cerebrovascular disorders: a clinical and research classification: World Health Organization; 1978. https://apps.who. int/iris/handle/10665/37194.

4. GBD 2016 Lifetime Risk of Stroke Collaborators, Feigin VL, Nguyen G, et al. Global, regional, and country-specific lifetime risks of stroke, 1990 and 2016. N Engl J Med. 2018;379(25):2429-37.

5. Wu S, Wu B, Liu M, Chen Z, Wang W, Anderson CS, et al. Stroke in China: advances and challenges in epidemiology, prevention, and management. Lancet Neurol. 2019;18(4):394-405. https://doi.org/10.1016/S1474-4422(18)3 0500-3.

6. Zhou M, Wang $\mathrm{H}$, Zeng Xet al. Mortality, morbidity, and risk factors in China and its provinces, 1990-2017: a systematic analysis for the global burden of disease study 2017. Lancet 2019:394(10204):1145-58. https://doi.org/10.1016/ S0140-6736(19)30427-1.
7. Wang YL, Wu D, Liao X, Zhang W, Zhao X, Wang YJ. Burden of stroke in China. Int J Stroke. 2007;2(3):211-3. https://doi.org/10.1111/j.1747-4949.2007. 00142.x.

8. Liu M, Wu B, Wang WZ, Lee LM, Zhang SH, Kong LZ. Stroke in China: epidemiology, prevention, and management strategies. Lancet Neurol. 2007; 6(5):456-64. https://doi.org/10.1016/S1474-4422(07)70004-2.

9. Wang W, Jiang $B$, Sun $H$, Ru X, Sun D, Wang $L$, et al. Prevalence, incidence, and mortality of stroke in China: results from a nationwide populationbased survey of 480687 adults. Circulation. 2017;135(8):759-71. https://doi. org/10.1161/CIRCULATIONAHA.116.025250.

10. Chen $\mathrm{YL}$, Yang $\mathrm{KH}$, Marusic A, et al. A reporting tool for practice guidelines in healthcare: the RIGHT statement. Ann Intern Med. 2017;166(2):128-32. https://doi.org/10.7326/M16-1565.

11. Page MJ, McKenzie JE, Bossuyt PM, et al. The PRISMA 2020 statement: an updated guideline for reporting systematic reviews. BMJ. 2021;372:n71.

12. Chinese Society of Neurology, Neurorehabilitation Society, Chinese Society of Neurology, Cerebrovascular Disease Society, Chinese Society of Neurology. Guidelines for early rehabilitation of stroke in China. Chin J Neurol, 2017, 50(06): 405-412. [In Chinese]

13. Expert Committee on Stroke Prevention and Control of National Health Commission. Guidelines for pre-hospital emergency stroke treatment. National Med J China. 2018,98(39):3138-47. https://doi.org/10.3760/cma.j. issn.0376-2491.2018.39.003.

14. Hong KS, Ko SB, Yu KH, et al. Update of the Korean Clinical Practice Guidelines for Endovascular Recanalization Therapy in Patients with Acute Ischemic Stroke. J Stroke. 2016;18(1):102-13. https://doi.org/10.5853/jos.2015.01655.

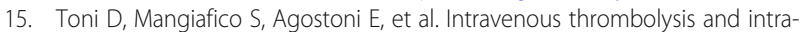
arterial interventions in acute ischemic stroke: Italian Stroke Organisation (ISO)-SPREAD guidelines. Int J Stroke, 2015;10(7):1119-29.

16. Liu L, Ding J, Leng $X$, et al. Guidelines for evaluation and management of cerebral collateral circulation in ischaemic stroke 2017, Stroke and vascular neurology. 2018;3(3):117-30.

17. Winstein C J, Stein J, Arena R, et al. Guidelines for adult stroke rehabilitation and recovery: a guideline for healthcare professionals from the American Heart Association/American Stroke Association. Stroke. 2016;47(6):e98-e169.

18. Torbey MT, Bösel J, Rhoney DH, et al. Evidence-based guidelines for the management of large hemispheric infarction : a statement for health care professionals from the Neurocritical Care Society and the German Society for Neuro-intensive Care and Emergency Medicine. Neurocrit Care. 2015; 22(1):146-64. https://doi.org/10.1007/s12028-014-0085-6.

19. Ntaios G, Dziedzic T, Michel P, Papavasileiou V, Petersson J, Staykov D, et al. European stroke organisation (ESO) guidelines for the management of temperature in patients with acute ischemic stroke. Int J Stroke. 2015;10(6): 941-9. https://doi.org/10.1111/ijs.12579.

20. Linden B. National Institute for health and care excellence NG128 stroke and transient ischaemic attack in over 16s: diagnosis and initial management. Br J Cardiac Nursing. 2020;15(9):1-5. https://doi.org/10.12968/ bjca.2020.0121.

21. Stoodley N. RCPCH clinical guideline, stroke in childhood: an evidencebased guideline for diagnosis, management, and rehabilitation. Clin Radiol. 2017;72:S25. https://doi.org/10.1016/j.crad.2017.06.104.

22. Hemphill JC 3rd, Greenberg SM, Anderson CS, et al. Guidelines for the Management of Spontaneous Intracerebral Hemorrhage: A Guideline for Healthcare Professionals From the American Heart Association/American Stroke Association. Stroke. 2015;46(7):2032-60. https://doi.org/10.1161/STR. 0000000000000069 .

23. Casaubon LK, Boulanger JM, Blacquiere D, et al. Canadian stroke best practice recommendations : hyperacute stroke care guidelines, update 2015 Int J Stroke. 2015;10(6):924-40. https://doi.org/10.1111/ijs.12551.

24. China Neurology Experts Group. Anhui province stroke hierarchical diagnosis and treatment guidelines [J]. Anhui Medicine,2016,37(04):367-382. [In Chinese].

25. Intercollegiate Stroke Working Party. National clinical guideline for stroke. Avaliable on:https://www.strokeaudit.org/SupportFiles/Documents/ Guidelines/2016-National-Clinical-Guideline-for-Stroke-5t-(1).aspx. Accessed 15 Sept 2021.

26. Charlotte D, Lisa L. Update: stroke guidelines. Nurs Manag. 2016;47(2):24-33 quiz 1.

27. Kim DH, Ko SB, Cha JK, et al. Updated Korean clinical practice guidelines on decompressive surgery for malignant middle cerebral artery territory infarction. J Stroke. 2015;17(3):369-76. 
28. Gao F, Xu A. Chinese guidelines for endovascular treatment of acute ischemic stroke 2015. Chin J Stroke. 2015;10(07):590-606. [In Chinese].

29. Liu M, He M-L. Chinese guidelines for the diagnosis and treatment of acute ischemic stroke 2014. Chin J Neurol. 2015;48(04):246-57 In Chinese.

30. National Stroke Association. Hope: The stroke recovery guide. Avaliable on: https://www.heart.org/en/health-topics/consumer-healthcare/order-america n-heart-association-educational-brochures/hope-stroke-recovery-guide. Accessed 15 Sept 2021.

31. Rivkin MJ, Bernard TJ, Dowling MM, et al. Guidelines for urgent management of stroke in children. Pediatr Neurol. 2016;56:8-17. https://doi. org/10.1016/j.pediatrneurol.2016.01.016

32. Saver JL. CLINICAL PRACTICE. Cryptogenic stroke. The New Engl J Med. 2016;374(21):2065-74. https://doi.org/10.1056/NEJMcp1503946.

33. Scheinfeld $\mathrm{MH}$, et al. A radiologist's guide to the clinical scales used in the 2015 endovascular stroke trials and the revised American Heart Association/ American Stroke Association guidelines for endovascular stroke treatment. Emerg Radiol. 2016;23(5):497-501. https://doi.org/10.1007/s10140-016-1420-3.

34. Sweis R, Biller J. Practical guide to direct new oral anticoagulant use for secondary stroke prevention in atrial fibrillation. Curr Treat Options Cardiovasc Med. 2016;18(4). https://doi.org/10.1007/s11936-016-0446-x.

35. Michelle G, Davis Andrew M. Guidelines for adult stroke rehabilitation and recovery. JAMA. 2018;319(8):820-1.

36. (Australian) Stroke Foundation. Clinical Guidelines for Stroke Management 2017. 2017. Available on: https://informme.org.au/en/Guidelines/ClinicalGuidelines-for-Stroke-Management-2017. Accessed 15 Sept 2021.

37. Tanya L. Medley et al. Australian clinical consensus guideline: the diagnosis and acute management of childhood stroke. Int J Stroke. 2019:14(1):94-106. https://doi.org/10.1177/1747493018799958.

38. Gao CY, Wu CH, Zhao JG, et al. Guidelines for the diagnosis and treatment of Chinese and Western medicine in cerebral infarction in China (2017). Chin J Integr Trad Chin West Med. 2018;38(02):136-44 In Chinese.

39. Blacquiere D, Lindsay MP, Foley N, Taralson C, Alcock S, Balg C, et al. Canadian stroke best practice recommendations: telestroke best practice guidelines update 2017. Int J Stroke. 2017;12(8):886-95. https://doi.org/10.11 77/1747493017706239.

40. Zheng $\mathrm{TH}$, Huang HM, Zhang $\mathrm{XL}$, et al. Guidelines for secondary prevention of stroke and transient ischemic attack (part VI). Chin J Stroke. 2015;10(01): 75-83 In Chinese.

41. Wang CJ, Wang CHX, Miao CR. Chinese guidelines for secondary prevention of ischemic stroke and transient ischemic attack 2014. Chin J Neurol. 2015; 48(04):258-73 In Chinese.

42. Peng B, Wu B. Chinese guidelines for the diagnosis and treatment of acute ischemic stroke 2018. Chin J Neurol. 2018;51(09):666-82 In Chinese.

43. Liu XF, Sun W, Zhu WS, et al. Guidelines for early endovascular interventional treatment of acute ischemic stroke in China 2018. Chin J Neurol. 2018;51(09):683-91. In Chinese.

44. Hu HH, Liu CX, Chen BL, et al. Guidelines for antiplatelet drug therapy in ischemic stroke 2016. Taiwan Stroke Society. Avaliable on: https://www. stroke.org.tw/GoWeb2/include/index.php?Page=3. [In Chinese]. Accessed 15 Sept 2021

45. Casaubon LK, et al. Canadian stroke best practice recommendations: acute inpatient stroke care guidelines, update 2015. Int J Stroke. 2016;11(2):23952. https://doi.org/10.1177/1747493015622461.

46. Hebert D, Lindsay MP, McIntyre A, Kirton A, Rumney PG, Bagg S, et al. Canadian stroke best practice recommendations: stroke rehabilitation practice guidelines, update 2015. Int J Stroke. 2016;11(4):459-84. https://doi. org/10.1177/1747493016643553.

47. Cameron II, et al. Canadian stroke best practice recommendations: managing transitions of care following stroke, guidelines update 2016. Int J Stroke. 2016;11(7):807-22. https://doi.org/10.1177/1747493016660102.

48. Wein T, Lindsay MP, Côté R, Foley N, Berlingieri J, Bhogal S, et al. Canadian stroke best practice recommendations: secondary prevention of stroke, sixth edition practice guidelines, update 2017. Int J Stroke. 2018;13(4):420-43. https://doi.org/10.1177/1747493017743062.

49. Boulanger JM, Lindsay MP, Gubitz G, Smith EE, Stotts G, Foley N, et al. Canadian stroke best practice recommendations for acute stroke management: prehospital, emergency department, and acute inpatient stroke care, 6th edition, update 2018. Int J Stroke. 2018;13(9):949-84. https:// doi.org/10.1177/1747493018786616.

50. Powers WJ, Rabinstein AA, Ackerson T, Adevoe OM, Bambakidis NC, Becker K. 2018 guidelines for the early management of patients with acute ischemic stroke: a guideline for healthcare professionals from the American Heart Association/American Stroke Association. J Vasc Surg. 2018;67(6):1934. https://doi.org/10.1016/j.jvs.2018.04.007.

51. Medley $T L$, et al. Australian clinical consensus guideline: the diagnosis and acute management of childhood stroke. Int J Stroke. 2019;14(1):94-106. https://doi.org/10.1177/1747493018799958.

52. Marques P-NO, et al. Brazilian guidelines for endovascular treatment of patients with acute ischemic stroke. Arq Neuropsiquiatr. 2017;75(1):50-6.

53. Qiang D, et al. The Chinese Stroke Association scientific statement: intravenous thrombolysis in acute ischaemic stroke. Stroke and Vascular Neurology. 2017;2(3):147-59.

54. Wang Y, Liu M, Chuanqiang P. 2014 Chinese guidelines for secondary prevention of ischemic stroke and transient ischemic attack. Int J Stroke. 2017;12(3):302-20. https://doi.org/10.1177/1747493017694391.

55. Guillaume T, et al. European stroke organisation (ESO) - European Society for Minimally Invasive Neurological Therapy (ESMINT) guidelines on mechanical thrombectomy in acute ischemic stroke. J Neurointervention Surgery. 2019;11:535.

56. Sang-Bae K, et al. 2019 update of the Korean clinical practice guidelines of stroke for endovascular recanalization therapy in patients with acute ischemic stroke. J Stroke. 2019;14:71.

57. Xiaochuan H, Gao F. Chinese guidelines for endovascular treatment of acute ischemic stroke 2018. Chin J Stroke. 2018;13(07):706-29 In Chinese.

58. Furie Karen L, Jayaraman MV. Guidelines for the early management of patients with acute ischemic stroke. 2018, Stroke;2018, 49(3):509-10.

59. Eskes GA, et al. Canadian stroke best practice recommendations: mood, cognition and fatigue following stroke practice guidelines, update 2015. Int J Stroke. 2015;10(7):1130-40. https://doi.org/10.1111/ijs.12557.

60. Zhang $S, X u Y$, Suiqiang $Z$. Chinese guidelines for the diagnosis and treatment of cerebral hemorrhage (2014). Chin J Neurol. 2015;48(06):435-44 In Chinese.

61. Greenham M, Knight S, RoddaPhD J, Scheinberg A, Anderson V, Fahey MC, et al. Australian clinical consensus guideline for the subacute rehabilitation of childhood stroke. Int J Stroke. 2021;16(3):311-20. https://doi.org/10.1177/1 747493020941279

62. Dual antiplatelet therapy with aspirin and clopidogrel for acute high risk transient ischaemic attack and minor ischaemic stroke: a clinical practice guideline. BMJ (Clinical research ed.), 2019, 364 : |103.

63. Zhu WS, Liu WH, Liu XF, et al. Guidelines for Early Endovascular Interventions in Acute Ischemic Stroke in China. Chin J Neurol.2015,48(05): 356-361.[In Chinese]

64. Chinese Society of Neurology; Chinese Stroke Society; Neurovascular Intervention Group of Chinese Society of Neurology. Chinese guidelines for the diagnosis and treatment of cerebral hemorrhage (2019). Chinese Journal of Neurology, 2019, 52(12):994-1005.[In Chinese]

65. Chinese Society of Neurology; Chinese Stroke Society; Neurovascular Intervention Group of Chinese Society of Neurology. Chinese guidelines for primary prevention of cerebrovascular disease 2019. Chinese Journal of Neurology,2019(09):684-709.[In Chinese]

66. Chinese Society of Neurology; Chinese Stroke Society; Neurovascular Intervention Group of Chinese Society of Neurology.Chinese guidelines for the diagnosis and treatment of subarachnoid hemorrhage 2019. Chinese Journal of Neurology,2019, 52(12):1006-1021.[In Chinese]

67. Cong F, Cui Y. Chinese evidence-based clinical practice guidelines for aquatic exercise therapy in stroke (2019 edition). Chin Rehabil Theory Practice. 2020;26(03):249-62 In Chinese.

68. Dong Yi, Wang Yilong, Liu Liping et al. Chinese guidelines for clinical management of cerebrovascular disease. Chin J Stroke, 2019, 14.[In Chinese]

69. Ko SB, Park HK, Kim BM, et al. 2019 Update of the Korean Clinical Practice Guidelines of Stroke for Endovascular Recanalization Therapy in Patients with Acute Ischemic Stroke. J Stroke. 2019;21(2):231-240. https://doi.org/10. 5853/jos.2019.00024

70. Turc G, Bhogal P, Fischer U, et al. European Stroke Organisation (ESO) European Society for Minimally Invasive Neurological Therapy (ESMINT) Guidelines on Mechanical Thrombectomy in Acute Ischaemic StrokeEndorsed by Stroke Alliance for Europe (SAFE). Eur Stroke J. 2019;4(1): 6-12. https://doi.org/10.1177/2396987319832140.

71. Powers William J et al. Guidelines for the early management of patients with acute ischemic stroke: 2019 Update to the 2018 guidelines for the early management of acute ischemic stroke: a guideline for healthcare professionals from the American Heart Association/American Stroke 
Association. Stroke, 2019, 50(12) : e344-e418 https://doi.org/10.1161/STR. 0000000000000211.

72. Christensen H, Cordonnier C, Körv J, Lal A, Ovesen C, Purrucker JC, et al. European stroke organisation guideline on reversal of oral anticoagulants in acute intracerebral haemorrhage. Eur Stroke J. 2019;4(4):294-306. https://doi. org/10.1177/2396987319849763.

73. Klijn CJM, et al. Antithrombotic treatment for secondary prevention of stroke and other thromboembolic events in patients with stroke or transient ischemic attack and non-valvular atrial fibrillation: a European stroke organisation guideline. Eur Stroke J. 2019;4(3):198-223. https://doi. org/10.1177/2396987319841187.

74. Lanctôt KL, et al. Canadian stroke best practice recommendations: mood, cognition and fatigue following stroke, 6th edition update 2019. Int J Stroke. 2020;15(6):668-88. https://doi.org/10.1177/1747493019847334.

75. Kazunori T, et al. Guidelines for intravenous thrombolysis (recombinant tissue-type plasminogen activator), the third edition, march 2019: a guideline from the Japan stroke society. Neurol Med Chir. 2019;59(12):44991. https://doi.org/10.2176/nmc.st.2019-0177.

76. Teasell R, Salbach NM, Foley N, Mountain A, Cameron JI, Jong A d, et al. Canadian stroke best practice recommendations: rehabilitation, recovery, and community participation following stroke. Part one: rehabilitation and recovery following stroke; 6th edition update 2019. Int J Stroke. 2020;15(7): 763-88. https://doi.org/10.1177/1747493019897843.

77. Yasha Kayan et al. Current endovascular strategies for posterior circulation large vessel occlusion stroke: report of the Society of Neurolnterventional Surgery Standards and Guidelines Committee. J Neurolnterventional Surgery. 2019;11(10):1055-62.

78. Xia Y, Chen YL, Zhao Z, et al. Using the RIGHT statement to evaluate the reporting quality of clinical practice guidelines in traditional Chinese medicine. PLoS One. 2018;13(11):e0207580. https://doi.org/10.1371/journal. pone.0207580

79. Wang Q, Duan Y, Liang J, Chen Z, Chen J, Zheng Y, et al. Reporting quality of 2014-2018 clinical practice guidelines on diabetes according to the RIGHT checklist. Endocrine. 2019;65(3):531-41. https://doi.org/10.1007/s1202 0-019-02005-9.

80. O'Donnell MJ, Chin SL, Rangarajan S, et al. Global and regional effects of potentially modifiable risk factors associated with acute stroke in 32 countries (INTERSTROKE): a case-control study. Lancet. 2016;388(10046):76175. https://doi.org/10.1016/S0140-6736(16)30506-2.

81. da Costa Santos CM, de Mattos Pimenta CA, Nobre MR. The PICO strategy for the research question construction and evidence search. Rev Lat Am Enfermagem. 2007;15(3):508-11. https://doi.org/10.1590/S0104-11692 007000300023.

82. Niforatos JD, Pescatore RM. Financial relationships with industry among guideline authors for the management of acute ischemic stroke. Am J Emerg Med. 2019 May;37(5):921-3. https://doi.org/10.1016/..ajem.2019.01.037.

83. Yuwen Y, Shi NN, Han XJ, Gao Y, Xu JL, Liu DS, et al. Appraisal of clinical practice guidelines for ischemic stroke management in Chinese medicine with appraisal of guidelines for research and evaluation instrument: a systematic review. Chin J Integr Med. 2015;21(9):707-15. [In Chinese]. https://doi.org/10.1007/s11655-014-1834-2.

84. Yang KH, Chen YL, Li YP, et al. Members of the Lanzhou international guideline symposium. Editorial: can China master the guideline challenge? Health Res Policy Syst. 2013;11:1 Published 2013 Jan 9.

85. Chen YL, Ma YF, Zhou Q, et al. Who should participate in the development of clinical practice guidelines? Med J Peking Union Med Coll Hospital. 2019; 10(05):524-30 [In Chinese].

\section{Publisher's Note}

Springer Nature remains neutral with regard to jurisdictional claims in published maps and institutional affiliations.

Ready to submit your research? Choose BMC and benefit from:

- fast, convenient online submission

- thorough peer review by experienced researchers in your field

- rapid publication on acceptance

- support for research data, including large and complex data types

- gold Open Access which fosters wider collaboration and increased citations

- maximum visibility for your research: over $100 \mathrm{M}$ website views per year

At BMC, research is always in progress.

Learn more biomedcentral.com/submissions 